\title{
Influence of Bondcoat Spray Process on Lifetime of Suspension Plasma-Sprayed Thermal Barrier Coatings
}

\author{
M. Gupta ${ }^{1}$ N. Markocsan ${ }^{1} \cdot$ X.-H. Li ${ }^{2}$ L. Östergren ${ }^{3}$
}

Submitted: 17 July 2017 / in revised form: 27 October 2017/Published online: 11 December 2017

(c) The Author(s) 2017. This article is an open access publication

\begin{abstract}
Development of thermal barrier coatings (TBCs) manufactured by suspension plasma spraying (SPS) is of high commercial interest as SPS has been shown capable of producing highly porous columnar microstructures similar to the conventionally used electron beam-physical vapor deposition. However, lifetime of SPS coatings needs to be improved further to be used in commercial applications. The bondcoat microstructure as well as topcoat-bondcoat interface topography affects the TBC lifetime significantly. The objective of this work was to investigate the influence of different bondcoat deposition processes for SPS topcoats. In this work, a NiCoCrAlY bondcoat deposited by high velocity air fuel (HVAF) was compared to commercial vacuum plasma-sprayed NiCoCrAlY and PtAl diffusion bondcoats. All bondcoat variations were prepared with and without grit blasting the bondcoat surface. SPS was used to deposit the topcoats on all samples using the same spray parameters. Lifetime of these samples was examined by thermal cyclic fatigue testing. Isothermal heat treatment was performed to study bondcoat oxidation over time. The effect of bondcoat deposition process and interface topography on lifetime in each case has been discussed.
\end{abstract}

This article is an invited paper selected from presentations at the 2017 International Thermal Spray Conference, held June 7-9, 2017, in Düsseldorf, Germany, that has been expanded from the original presentation.

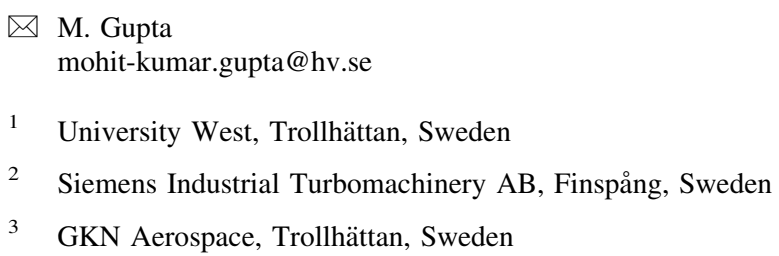

The results show that HVAF could be a suitable process for bondcoat deposition in SPS TBCs.

Keywords bondcoats - high velocity air fuel spraying . interface topography $\cdot$ lifetime $\cdot$ suspension plasma spraying $\cdot$ thermal barrier coatings

\section{Introduction}

A thermal barrier coating (TBC) system is designed to protect a gas turbine component from high temperatures and harsh environments. Improvements in gas turbine efficiency are highly desired by the gas turbine industry as it would result in higher fuel efficiency as well as lower emissions (Ref 1). One way of achieving higher turbine efficiency is to increase the operating temperatures which implies that the TBCs should provide better thermal insulation to the metallic component (Ref 2). TBCs produced by suspension plasma spraying (SPS) can significantly improve their thermal insulation ability due to a very fine porous microstructure which provides very high phonon scattering due to the well-dispersed multiscale porosity (Ref 3-5). SPS TBCs are of significant commercial interest as the technique is considerably cheaper than commercially used electron beam-physical vapor deposition (EB-PVD), both in terms of equipment cost and running cost (Ref 6). In addition, the SPS process has higher deposition rates than EB-PVD and the layers are porous so that the thermal conductivity is significantly reduced as compared to EBPVD and other thermal spray processes (Ref 5, 7). Further improvements in reliability and lifetime of SPS TBCs that enables an alternative to the EB-PVD process would result in huge cost savings as well as lower emissions. 
Lifetime of a TBC system is strongly dependent on bondcoat microstructure, fabrication process as well as topcoat-bondcoat interface topography (Ref 8-11). The bondcoat layer in EB-PVD TBCs is typically deposited by vacuum plasma spraying (VPS) in case of NiCoCrAlY bondcoats and diffusion process in case of platinum-modified aluminide (PtAl) bondcoats, while in the case of atmospheric plasma-sprayed TBCs, the NiCoCrAlY bondcoats are typically deposited by high velocity oxy-fuel (HVOF) spraying or VPS. It is not fully understood yet which bondcoat deposition process would be most suitable for SPS TBCs as the deposition process affects the bondcoat microstructure and interface topography, which in turn affects TBC lifetime.

Previous studies have highlighted the importance of controlling the bondcoat surface topography in SPS TBCs as the bondcoat roughness has a significant influence on the column formation in SPS topcoats as well as TBC lifetime (Ref 12-16). It is understood that the protrusions on the bondcoat surface support in formation of columns in the topcoat (Ref 12, 13). Even though columns could be formed on smooth bondcoat surfaces as well (Ref 14, 16), the resulting columnar microstructure would be different due to possibly higher number of column initiation points formed due to the multiple large particles deposited on the bondcoat surface in the first few spray runs (Ref 17). A smoother bondcoat surface typically results in higher number of columns with lower column width and intercolumnar gap (Ref 14-16). This implies that optimization of topcoat and bondcoat microstructures should be done in parallel in order to make sure that the desired topcoat microstructure could actually be achieved with the optimized bondcoat microstructure and surface topography. Even though the bondcoat surface topography could be modified by surface treatment processes like grit blasting and shot peening, it is desired to keep these additional steps to a minimum to reduce the costs. In case of atmospheric plasma-sprayed (APS) topcoats, it is typically desired to have a rough bondcoat surface (in the range 6-12 $\mu \mathrm{m}$ ) for good adhesion and long lifetime of the coating (Ref 18). On the contrary, it has been shown in earlier works that a smoother bondcoat results in a higher thermal cyclic lifetime of the SPS TBC, perhaps due to the compact columnar topcoat microstructure created due to the low surface roughness as well as better adhesion of the topcoat due to a higher contact surface area (Ref 14, 16). Curry et al. created a smooth bondcoat surface by polishing the surface of bondcoat sprayed by high velocity air fuel (HVAF), while Bernard et al. used the inherently smooth platinum-diffused $\mathrm{Ni} / \mathrm{Ni}_{3} \mathrm{Al}$ bondcoat ( $\left.\operatorname{Ref} 14,16\right)$.

In previous work, HVAF has shown promising results as bondcoat deposition method in SPS TBCs in order to achieve high lifetime (Ref 19, 20). HVAF is a cheap and energy-efficient process as it uses compressed air as oxidant instead of oxygen as in HVOF and does not require a special vacuum chamber for spraying as in VPS. HVAF could be a more suitable process than HVOF for SPS TBCs as due to the higher particle velocity and lower particle temperature in HVAF process, it has the potential to create smoother and denser bondcoat layers which were shown to be beneficial for lifetime of SPS TBCs as discussed above. Moreover, due to low dwell time and particle temperature, the particles are not fully molten during the process resulting in low depletion of beta-phase and low particle oxidation during spraying. The presence of beta-phase as one on the main phases in HVAF-sprayed NiCoCrAlY bondcoat has been confirmed by X-ray diffraction analysis in previous work (Ref 21). Another work has also shown denser TGO layers and lower amount of mixed oxides with HVAF bondcoats resulting in higher lifetimes as compared to HVOF and APS bondcoats (Ref 19). The coatings are also denser which implies a low level of internal oxidation under thermal exposure (Ref 19).

In this work, HVAF bondcoat was compared to commercial VPS and diffusion bondcoats, used currently for certain gas turbine components in industry, for application in SPS TBCs. The objective of this work was to investigate the relationships between bondcoat microstructure, topcoat-bondcoat interface topography, and lifetime in SPS TBCs. All bondcoats were prepared with and without grit blasting the bondcoat surface. Lifetime of the samples was investigated by thermal cyclic fatigue (TCF) testing, while isothermal heat treatment of the coatings was performed to study bondcoat oxidation over time. The long-term goal of this ongoing research work is to develop a bondcoat layer that is most suitable for SPS TBCs in order to achieve high coating lifetime.

\section{Experimental}

\section{Sample Preparation}

Three bondcoat processes were investigated in this studyHVAF, VPS, and diffusion coating. NiCoCrAlY (AMDRY 386-2, Oerlikon Metco) was used for HVAF and VPS as the bondcoat material. These two bondcoats were compared to the diffusion bondcoat. The HVAF bondcoat was sprayed with the M3 supersonic HVAF spray gun (Uniquecoat Technologies, USA) using the spray parameters based on prior experience with the process. The VPS and diffusion bondcoats were ordered from commercial suppliers. The thickness of the HVAF bondcoat was around $200 \mu \mathrm{m}$, VPS bondcoat was around $160 \mu \mathrm{m}$, and diffusion bondcoat was around $75 \mu \mathrm{m}$ in as-sprayed condition. 
As the influence of bondcoat surface roughness on TBC lifetime was also of interest in this study, some samples from each set were grit-blasted prior to the topcoat deposition. A light grit blasting with a robotized pressure feed grit blasting gun using grit size 80 was performed over some of the samples of each bondcoat after the bondcoat spraying. The selected grit blasting parameters would normally result in a roughness of approximately $\mathrm{Ra}=3 \mu \mathrm{m}$ on plain uncoated steel substrates.

After the grit blasting step, both grit-blasted and nongrit-blasted samples were sprayed with topcoats using the same spray parameters. The topcoats were sprayed by SPS using the Mettech Axial III gun with NanoFeed 350 suspension feeder (Northwest Mettech Corp., Canada). The topcoat material was 8 wt.\% yttria-stabilized zirconia (YSZ) suspension in ethanol with $25 \%$ solid load. The samples were preheated with five strokes of the plasma gun prior to topcoat spraying reaching a substrate temperature at the start of topcoat deposition of about $250{ }^{\circ} \mathrm{C}$. The topcoat thickness was around $260 \mu \mathrm{m}$.

Substrates in dimensions $25.4 \mathrm{~mm}$ diameter $\times 6 \mathrm{~mm}$ thickness (coupons) were used for microstructure analysis and isothermal heat treatment, while substrates in dimensions $50 \mathrm{~mm} \times 30 \mathrm{~mm} \times 6 \mathrm{~mm}$ (plates) were used for TCF testing. The substrate material for TCF plates for all coatings and HVAF bondcoat coupons was Hastelloy-X, while for VPS and diffusion bondcoat coupons, substrate material was Inconel 792.

\section{Surface Topography}

3D surface topography of bondcoat samples in as-sprayed condition (before spraying topcoat layer) was measured by white light interferometry technique (MicroXAM, ADE Phase Shift Technology, USA) at Toponova, Sweden. Each scan covered an area of around $800 \mu \mathrm{m} \times 600 \mu \mathrm{m}$. The lateral resolution obtained with this technique was $1.1 \mu \mathrm{m}$ along the length and $1.3 \mu \mathrm{m}$ along the width, while the vertical resolution was $1 \mathrm{~nm}$. The captured data were analyzed with the software MountainsMAP ver. 6 (DigitalSurf, France) to post-process the data and to compute ISO 25178 parameters.

2D surface topography of the bondcoat samples before and after grit blasting was measured by contact profilometer. Six measurements were carried out by the profilometer on each sample.

\section{Microstructure}

After spraying the topcoats, one sample from each set was prepared for metallography analysis. The samples were first cold mounted in low viscosity epoxy resin, then sectioned using a cutting disk, and then cold mounted again in high viscosity epoxy resin for grinding and polishing. The polishing was performed automatically using a Buehler Power Pro 5000 equipment. The failed samples after lifetime testing and samples after isothermal heat treatment were also prepared in the same way.

Microstructures of all samples were analyzed by scanning electron microscopy (SEM) using a Hitachi TM3000 tabletop SEM equipment.

\section{Thermal Cyclic Fatigue Testing}

TCF testing is one of the common lifetime tests performed to analyze the performance of TBCs under cyclic heating and cooling under long-term exposures at high temperatures. Due to the long exposure, this test allows for significant oxide growth due to bondcoat oxidation. Swelling of thermally grown oxide (TGO) and mismatch in thermal expansion coefficient of different layers in the TBC system during cycling are the main driving mechanisms leading to failure in TCF testing. Sintering of topcoat during the heating cycle as well as thermal fatigue of the coating due to thermal cycling also plays a significant role in failure.

In this study, TCF testing was performed at Siemens Industrial Turbomachinery, Sweden. During this test, the samples were first heated in a furnace at $1100{ }^{\circ} \mathrm{C}$ for one hour and then cooled down to approximately $100{ }^{\circ} \mathrm{C}$ in 10 minutes by blowing compressed air on the coating surface of the samples. The heating and cooling cycles were repeated in this fashion until failure, which was determined by $20 \%$ spallation of the topcoat. The samples were photographed after each cycle to determine the failure.

Two samples of each coating set were tested by TCF testing in this study.

\section{Isothermal Heat Treatment}

The formation of TGO over time in different bondcoats was investigated by performing isothermal heat treatment of the samples. This was carried out by exposing the samples to a dwell temperature of $1100{ }^{\circ} \mathrm{C}$ in a furnace for a period of $10,50,100$, and $200 \mathrm{~h}$ in air environment. The heating rate of the samples from room temperature to $1100{ }^{\circ} \mathrm{C}$ was $5{ }^{\circ} \mathrm{C} / \mathrm{min}$. At the end of the dwell period, the samples were cooled down at a rate of maximum $5{ }^{\circ} \mathrm{C} / \mathrm{min}$. It was not possible to have forced cooling in the furnace.

\section{Results and Discussions}

\section{Bondcoat Surface Topography}

Precise measurement of bondcoat surface topography and careful assessment of the measurement data are essential to 
understand $\mathrm{TBC}$ failure mechanisms and subsequently enhance their lifetime. It has been shown in earlier work that only $\mathrm{Ra}$ as a roughness parameter is not sufficient to characterize a surface as surfaces with similar Ra can have different density of peaks, etc. and influence TBC lifetime (Ref 11). Measurement of 3D topography of samples is thus highly beneficial to analyze the topography of different samples as it provides high-resolution data with much better visualization and reliability than $2 \mathrm{D}$ topography data.

The bondcoat surface roughness data of different samples measured by contact profilometer before and after grit blasting are shown in Table 1. Light grit blasting of bondcoat samples was performed to remove high protrusions on the bondcoat surface as these features could induce high stresses during thermal cycling and be detrimental to TBC lifetime (Ref 11). It can be seen in Table 1 that the HVAF bondcoat showed the highest roughness both before and after grit blasting, while the VPS bondcoat showed a bit lower value. Grit blasting slightly reduced the surface roughness in both HVAF and VPS bondcoats, suggesting that the high protrusions on the bondcoat surface were at least partially removed. On the other hand, the diffusion showed the lowest surface roughness by far among all bondcoats which was slightly increased after grit blasting as it would normally do on a smooth surface. Although grit blasting is typically done to increase the roughness, only light grit blasting parameters were chosen in this case mainly to remove the high protrusions on the surface of the bondcoat.

The bondcoat surface profiles captured using white light interferometry technique in as-sprayed condition are shown in Fig. 1. It can be clearly noticed that all three surfaces have significantly different surface features. The HVAF bondcoat surface consists of mainly hemispherical hills evenly spread out along with a few high hills as indicated in Fig. 1(a). The reason for this type of surface profile is believed to be the low process temperature in HVAF spraying as well as a bit wide particle size distribution of the powder feedstock, resulting in incomplete melting of the larger particles. These semi-molten particles then adhere on the surface and form the hemispherical hills. As the larger particles in the feedstock material would be only

Table 1 Bondcoat surface roughness measured by contact profilometer before and after grit blasting

\begin{tabular}{lcc}
\hline Sample & \multicolumn{2}{c}{ Bondcoat roughness Ra, $\mu \mathrm{m}$} \\
\cline { 2 - 3 } & \multicolumn{1}{c}{ Before } & After \\
\hline HVAF & $8.11 \pm 1.23$ & $7.17 \pm 0.68$ \\
VPS & $6.77 \pm 0.75$ & $6.19 \pm 0.52$ \\
Diffusion & $1.13 \pm 0.29$ & $1.35 \pm 0.28$ \\
\hline
\end{tabular}

partially molten, these particles could result in the high hills present on the HVAF bondcoat surface. The lateral size of the high hills in Fig. 1(a), around 50-80 $\mu \mathrm{m}$, corresponds well to the larger size particles in the AMDRY 386-2 powder which has a powder cut of $-88+16 \mu \mathrm{m}$.

The VPS bondcoat surface shown in Fig. 1(b) consists of several closely spaced sharp hills as also indicated in the figure along with smaller hills evenly spread out. The reason for this type of surface profile is believed to be the high process temperature in VPS resulting in completely molten particles that could splash on the surface and create the small steep hills. The sharp hills could also have been created by the larger particles in the feedstock powder which could not have been completely molten.

The diffusion bondcoat surface shown in Fig. 1(c) consisted of a very smooth profile (please note the different vertical scale bar) with evenly distributed small hills and valleys. The low roughness of diffusion bondcoat resulted from the diffusion process adapted to EB-PVD topcoats which require very smooth bondcoat surfaces.

\section{Microstructure}

The microstructure images of the samples in as-sprayed condition with non-grit-blasted (left) and grit-blasted (right) bondcoats are shown in Fig. 2. It can be observed that both HVAF and VPS bondcoats shown in Fig. 2(a) and (b), respectively, had a dense microstructure with low porosity in the range of $2-4 \%$. The porosity in the HVAF bondcoat was mainly in the form of delaminations along the splat boundaries as indicated by the arrows in the figure with only few globular voids. In the VPS bondcoat, the porosity was mainly in the form of globular voids which can be seen as the dark areas in the bondcoat layer also indicated by arrows in the figure. The topcoats showed a columnar structure typically produced by SPS on these bondcoats with quite similar column density and porosity. This was expected as the topcoats were sprayed using the same spray parameters and the bondcoats had a close $R a$ roughness. No significant difference between the topcoats on non-grit-blasted and grit-blasted bondcoats could be observed for both HVAF and VPS bondcoats.

The diffusion bondcoat shown in Fig. 2(c) had a typical microstructure created by diffusion coating. Due to the low roughness of the bondcoat, very thin columns were created in the topcoat even though same spray parameters were used for all samples. This phenomenon has also been observed in previous work where low bondcoat roughness resulted in thin columns due to higher number on initiation peaks for column formation (Ref 14, 16). Due to the smooth bondcoat surface, the initiation peaks required for column formation are created by the large particles that adhere on the substrate's surface during the first few layers 


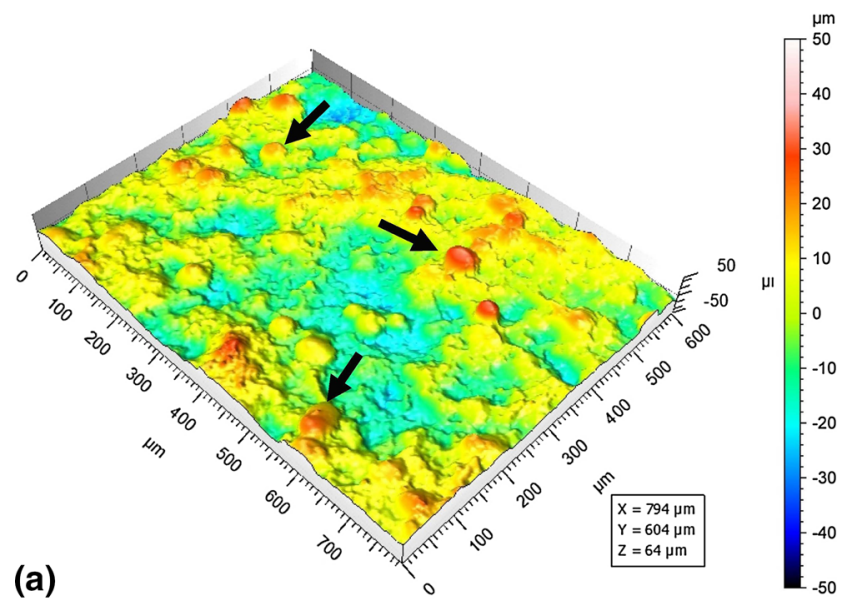

(b)

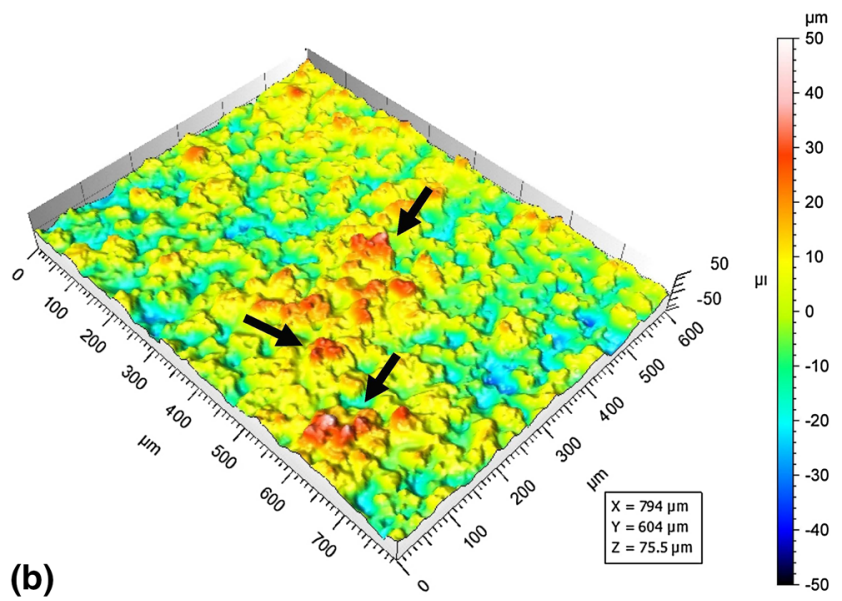

(c)

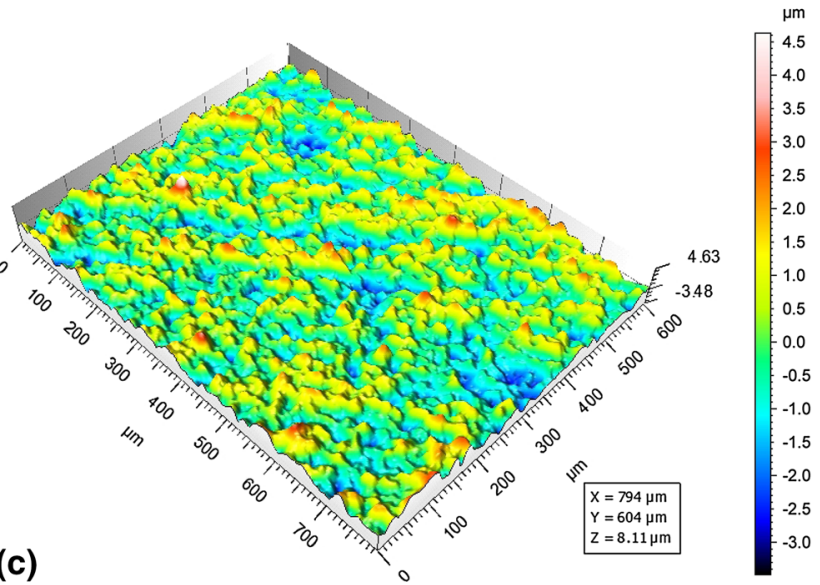

Fig. 1 Bondcoat surface profiles captured using white light interferometry technique on (a) HVAF, (b) VPS, and (c) diffusion samples in assprayed state

of deposition (Ref 17). Rough surfaces tend to have fewer column initiation peaks that are larger in size, resulting in wider and fewer columns (Ref 14). The topcoat microstructure on diffusion bondcoat looked very similar to an EB-PVD topcoat which usually exhibits high strain tolerance. However, due to the very low roughness of the diffusion bondcoat $(\sim 1 \mu \mathrm{m})$, the bonding of the SPS topcoats was very poor due to poor mechanical bonding unlike EB-PVD topcoats where chemical bonding is the major bonding mechanism. This resulted in complete spallation of the topcoat during metallography preparation as can be noticed in Fig. 2(c). Again, no significant difference between the topcoat microstructures in non-gritblasted and grit-blasted bondcoats could be observed.

The poor adhesion of the topcoat on diffusion bondcoat could perhaps be improved by isothermal heat treatment of the bondcoat prior to topcoat deposition as found beneficial in previous work (Ref 16). The heat treatment of bondcoat could improve topcoat adhesion through chemical bonding due to growth of a thin TGO layer of alumina (Ref 16). Another way of improving adhesion would be to further increase the roughness of diffusion bondcoat to achieve better mechanical bonding. The adhesion could perhaps also be improved by optimization of process parameters as same topcoat parameters were used for all bondcoats in this study.

Figure 3 shows the microstructure images of the HVAF samples in as-sprayed condition with non-grit-blasted (left) and grit-blasted (right) bondcoats. It can be observed in the figure that before grit blasting, some semi-molten particles creating a hemispherical hill can be found at the bondcoat interface close to topcoat as also indicated by the arrows. These particles were also observed in the bondcoat surface profile before grit blasting shown in Fig. 1(a). However, as it can be observed in Fig. 3, these hemispherical hills cannot be found after grit blasting of the bondcoat surface, indicating that the grit blasting step was successful in removing at least most of these particles over the HVAF bondcoat surface as desired. This observation was also suggested by the lower Ra roughness achieved after grit blasting as shown in Table 1. However, the grit blasting step did not affect the topcoat microstructure significantly 

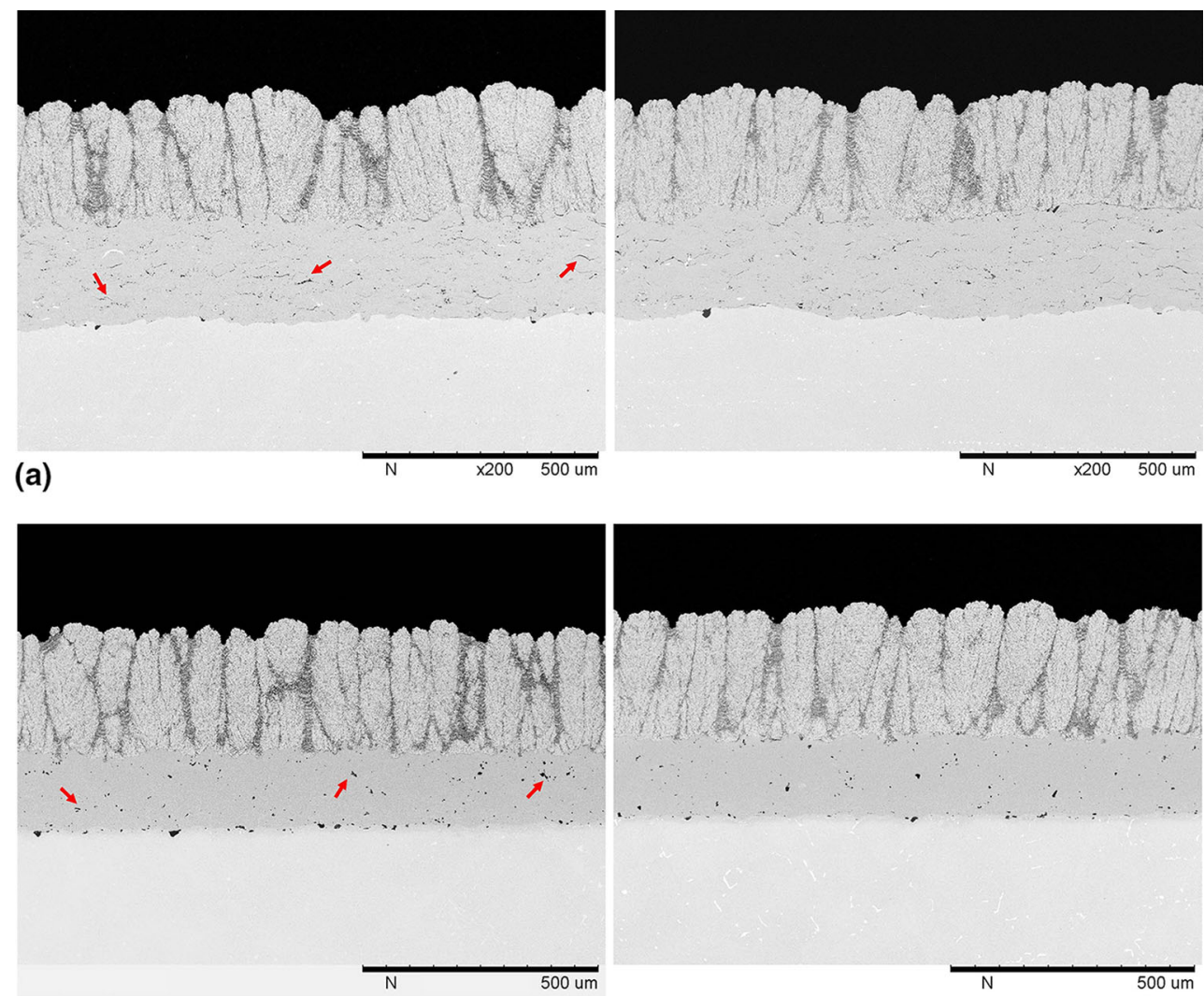

(b)
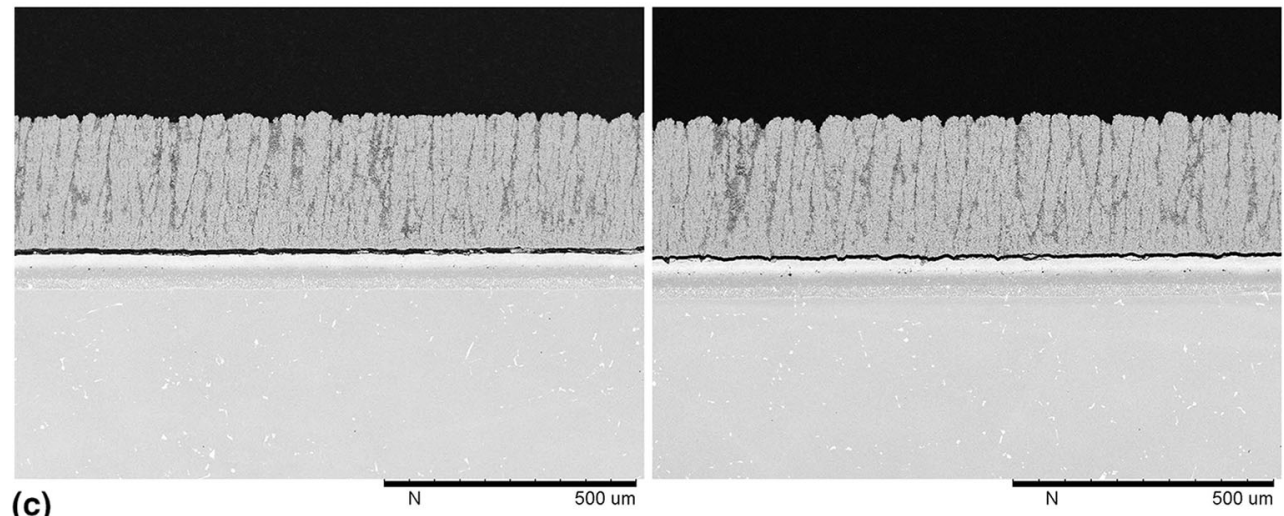

Fig. 2 Microstructure cross-sectional images of samples in as-sprayed condition with non-grit-blasted (left) and grit-blasted (right) bondcoats (a) HVAF, (b) VPS, and (c) diffusion

in all samples as observed in Fig. 2, perhaps due to insufficient change in the surface roughness after grit blasting as compared to the initial surface roughness.

Figure 4 shows the SEM images of the top view of the TBC samples in as-sprayed condition with (left) HVAF, (middle) VPS, and (right) diffusion bondcoats. In the top row images shown at low magnification, it can be observed that all topcoats had a typical cauliflower structure exhibited by SPS coatings. However, while the HVAF and VPS samples had similar column sizes and structures, the diffusion sample had much smaller column sizes as compared to the other two samples even though all topcoats were sprayed with the same spray parameters. The reason for this difference can be attributed directly to the initial bondcoat surface roughness which controls the column size and structure in the SPS topcoat microstructure due to differences in the number of initiation peaks for column formation (Ref 13, 14). These differences in the topcoat microstructures correlate well with the observations in Fig. 2.

The bottom row in Fig. 4 shows the top view images at high magnification. These images were captured at the 

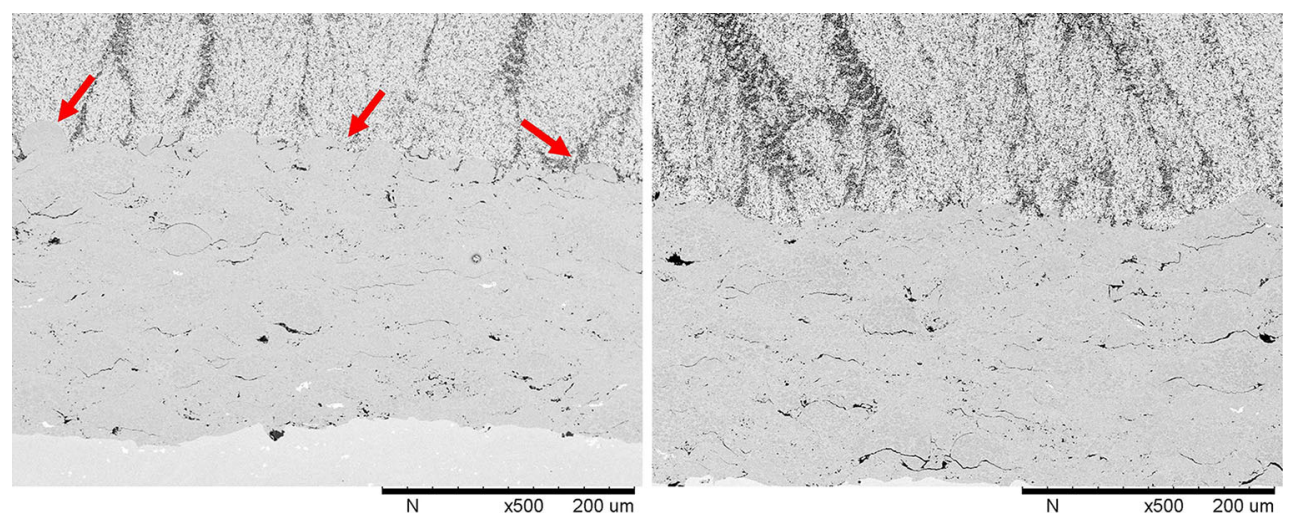

Fig. 3 Microstructure cross-sectional images of HVAF samples in as-sprayed condition with non-grit-blasted (left) and grit-blasted (right) bondcoats
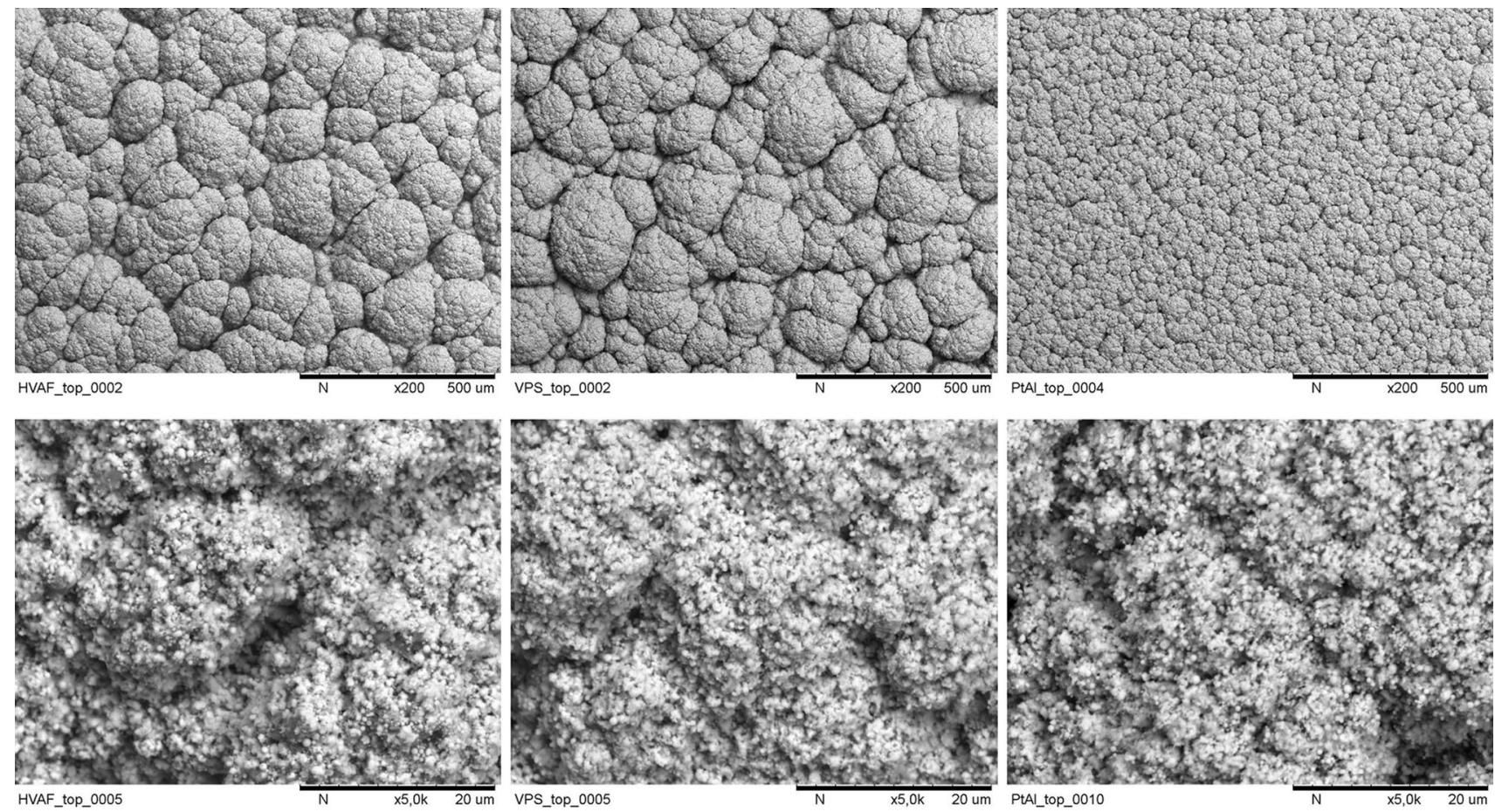

Fig. 4 SEM images of the top view of samples in as-sprayed condition (left) HVAF, (middle) VPS, and (right) diffusion with non-grit-blasted bondcoats. The top row shows the images at low magnification, while the bottom row shows the images at high magnification

center of randomly selected columns covering only a fraction of the column top surface due to the high magnification, thus avoiding the intercolumnar region. The columns in all three topcoats showed a very similar microstructure with similar porosity and particle sizes at high magnification even though the low magnification images showed significantly different column sizes. This result was somehow expected as same spray parameters were used for all topcoats using the same suspension feedstock resulting in similar droplet sizes, temperatures, and velocities. The results in Fig. 4 imply that for a given suspension, although the column size and structure in the topcoat microstructure are extensively influenced by the bondcoat roughness, the coating microstructure and porosity within the individual columns are mainly controlled by the spray parameters and are not significantly influenced by differences in column size and structure created due to differences in bondcoat roughness.

\section{Thermal Cyclic Fatigue Testing}

The results from TCF testing are shown in Fig. 5. All tested samples showed good TCF lifetimes, fulfilling the industrial requirements for this type of test. Between the HVAF and VPS samples that were sprayed with the same feedstock material, HVAF bondcoat showed around $20 \%$ 
higher TCF lifetime on average over grit-blasted and nongrit-blasted VPS samples. Both HVAF and VPS samples showed a slightly lower TCF lifetime with grit-blasted bondcoats, indicating that grit blasting did not improve the lifetime as expected. This could be because of the low change in roughness of the bondcoats after grit blasting due to the parameters chosen in this case that could have made the effect of grit blasting insignificant. A more comprehensive study with grit blasting parameters needs to be performed to understand the effect of grit blasting on lifetime of SPS TBCs.

The diffusion bondcoat showed the highest TCF lifetime among all bondcoats, although high standard deviation between the samples can be noticed. The average TCF lifetime of diffusion bondcoat samples was a bit higher with grit-blasted bondcoats indicating better adhesion of the SPS topcoat in case of a low initial roughness of the bondcoat.

The difference in TCF lifetimes of different samples could be due to various reasons, such as different TGO quality, TGO growth rates, topcoat-bondcoat interface topography as well as topcoat microstructure.

\section{Effect of Topcoat Microstructure}

Figure 6 shows the microstructure cross-sectional images of the samples after failure in TCF testing. It can be clearly observed that in all samples, failure occurred due to complete spallation of the topcoat due to cracking, mainly at the topcoat-TGO interface along with cracking within the TGO as well as at the TGO-bondcoat interface. This type of failure is understood to occur mainly due to the swelling of TGO and thermal mismatch stresses close to the topcoat-bondcoat interface during thermal cycling (Ref 19, 20). Opening up of the column gaps (indicated by the arrows in the topcoat layer in the images on the left) can be also be observed in all cases. This phenomenon is understood to occur due to sintering of the topcoat

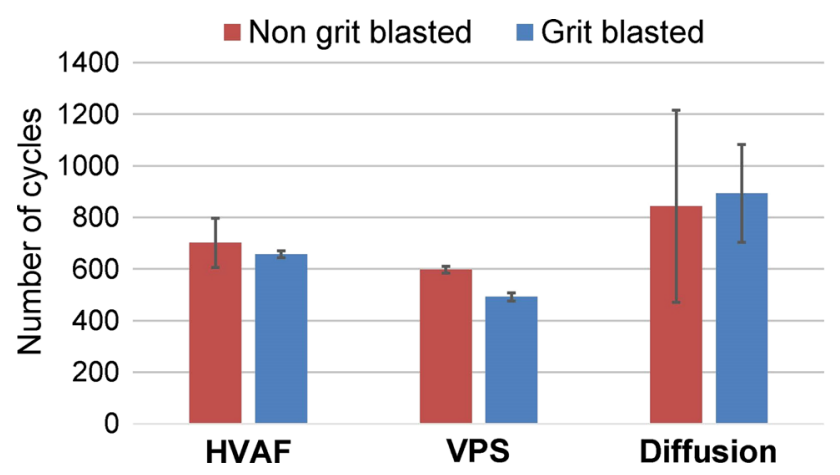

Fig. 5 Thermal cyclic fatigue lifetime results microstructure which results in shrinkage of the columns resulting in opening of column gaps due to mismatch stresses on the topcoat layer ( $\operatorname{Ref} 20,22)$. In case of the diffusion sample that had very thin columns in the topcoat in as-sprayed condition, some columns have partially merged together due to sintering, while other column gaps have partially opened up resulting in an inhomogeneous columnar structure after TCF testing as shown in Fig. 6(c). Propagation of cracks along the porous areas in the topcoat can also be observed in all cases, especially pronounced in the diffusion sample with the inhomogeneous columnar structure. It has been shown in previous work that the porous areas in the topcoat layer act as weak links in the topcoat and promote crack propagation (Ref 20).

\section{Effect of TGO Formation}

It can be observed in Fig. 6(a) that the HVAF sample had a thin and uniform layer of TGO consisting of mainly alumina seen as the dark gray layer at the topcoat-bondcoat interface without a significant presence of mixed oxides that could be typically seen by their light gray color. On the other hand, the VPS bondcoat showed some internal oxidation close to the topcoat-bondcoat interface resulting in an uneven layer of TGO with mainly alumina, but also some mixed oxides as indicated by the arrow in the image on the right in Fig. 6(b). It can also be observed in Fig. 6(a) and (b) that the beta-phase was still present in both bondcoats after failure in TCF testing, showing that there was still an aluminum reservoir left in the bondcoat (though smaller in the VPS bondcoat) and failure did not occur due to chemical failure of the bondcoat (Ref 10). This result indicates that the lower thickness of the VPS bondcoat as compared to the HVAF bondcoat did not have an influence on the TCF lifetime as the failure did not occur due to depletion of aluminum reservoir. These results show that HVAF could be a suitable alternative to VPS for bondcoat deposition in SPS TBCs.

In case of the diffusion sample after TCF testing shown in Fig. 6(c), it can be observed that a thin and uniform layer of pure alumina shown by the dark gray layer was formed. The reason for high TCF lifetime of diffusion bondcoats is deemed to be due to the different chemical composition of the bondcoat which results in a uniform and slow growing pure alumina layer without any detrimental oxides such as chromia, spinel, nickel oxide, as well as the high strain tolerance of the topcoat microstructure with very thin columns similar to a EB-PVD topcoat.

The rate of TGO growth and TGO quality in different samples is discussed further in "Isothermal Heat Treatment" section. 

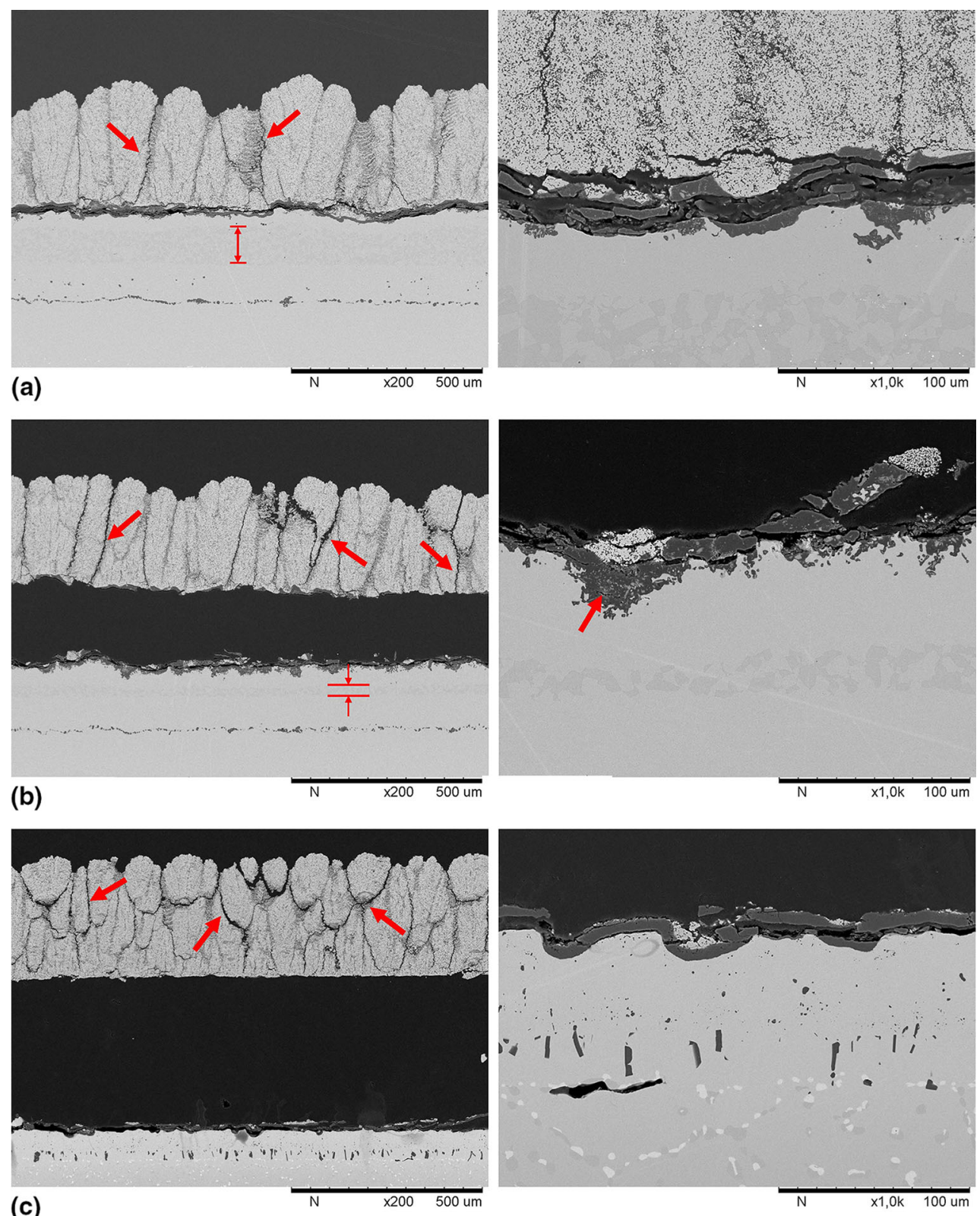

Fig. 6 Microstructure cross-sectional images of the samples after failure in TCF testing (a) HVAF, (b) VPS, and (c) diffusion with grit-blasted bondcoats. Images on the left show overview of the TBCs, while images on the right show TGO at a higher magnification

\section{Effect of Interface Topography}

Another reason for lower lifetime of VPS samples than HVAF samples, apart from the higher rate of bondcoat oxidation as discussed above, could have been the difference in bondcoat surface topography between the samples. Some of the ISO 25178 feature parameters measured on the HVAF and VPS bondcoat surfaces in as-sprayed condition are shown in Table 2. These parameters give a quantitative representation of the images shown in Fig. 1(a) and (b). It can be noted from Table 2 that HVAF bondcoat had a lower $S p d$ (density of peaks), slightly lower $S p c$ (arithmetic mean peak curvature), and similar $\mathrm{S} 10 z$ (ten point height) as compared to the VPS bondcoat. These numbers indicate that on average, HVAF bondcoat surface had wider peaks (due to lower $S p d$ ) with similar heights (due to similar $S 10 z$ ) and slightly lower curvature than the VPS bondcoat surface. It has been shown in previous work that for a given amplitude of the hill on bondcoat surface, the stresses in topcoat near the topcoat-bondcoat surface decrease significantly by increasing the lateral dimension of the hill, and vice versa (Ref 23). This implies that a narrow and sharp hill as in VPS bondcoat would induce much higher stresses in the topcoat than a wide and flat hill as in HVAF 
bondcoat. These induced stresses are particularly high close to the topcoat-bondcoat surface where failure usually occurs (Ref 23), which could have been the reason for earlier failure of the VPS samples. It must be noted here that the topography images only represent a fraction of the coating surface $(800 \mu \mathrm{m} \times 600 \mu \mathrm{m})$, and thus, these results should only be considered as indicative.

The poor bonding of SPS topcoats on diffusion bondcoats did not seem to deteriorate the TCF lifetime of these samples perhaps due to the uniform and slow growing TGO layer and low heating and cooling rates in TCF testing and thus low induced stresses that may have caused early spallation of the topcoat. Additionally, it is believed that the initial residual stresses in the coating in as-sprayed condition are typically relaxed in a few hours during TCF testing due to high creep rates in the ceramic coatings (Ref 24). The first few cycles in TCF testing could have also improved the adhesion of the topcoat through chemical bonding due to growth of a thin TGO layer of alumina similar to the isothermal heat treatment of the bondcoat performed in previous work to improve topcoat adhesion (Ref 16). However, the reason for high standard deviation in lifetime between the samples during TCF testing could have been the initial poor adhesion of the topcoat and different extent of improvements in bonding between the samples during the first cycles during TCF testing.

\section{Isothermal Heat Treatment}

Since it is not possible to observe the gradual bondcoat oxidation in case of TCF testing where only the microstructure after failure can be observed, the isothermal heat treatment study was performed to investigate bondcoat oxidation and TGO growth rate with time. Figure 7 shows the microstructure cross-sectional images of the samples after the isothermal heat treatment at $1100{ }^{\circ} \mathrm{C}$ for 10,50 , 100 , and $200 \mathrm{~h}$. No significant internal oxidation can be observed in any of the samples.

It can be observed in Fig. 7(a) that the HVAF bondcoat oxidized gradually as expected over time. A dense and
Fig. 7 Microstructure cross-sectional images of the samples after isothermal heat treatment at $1100{ }^{\circ} \mathrm{C}$ for (top left) $10 \mathrm{~h}$, (top right) $50 \mathrm{~h}$, (bottom left) $100 \mathrm{~h}$, and (bottom right) $200 \mathrm{~h}$ (a) HVAF, (b) VPS, and (c) diffusion with non-grit-blasted bondcoats

uniform dark gray layer of alumina can be clearly seen without any cracks except after $200 \mathrm{~h}$ where cracking was observed after metallography preparation. A few light gray regions of mixed oxides can also be observed at all stages as also indicated by the arrows in the figure. It is well known that mixed oxides can form at an early stage during exposure to high temperatures known as the 'transient stage' of oxidation (Ref 18). The beta-phase layer can still be observed in the bondcoat after $200 \mathrm{~h}$ indicating the presence of aluminum reservoir for further growth of the protective alumina layer. The thickness of the TGO layer after $200 \mathrm{~h}$ was about 8-10 $\mu \mathrm{m}$. It can be concluded from these observations that a dense and uniform layer of alumina without any cracks was produced in the HVAF bondcoat which is typically desired as it could prevent the bondcoat from detrimental oxidation. Due to limited number of samples, another set of HVAF bondcoats sprayed with same parameters, but lower bondcoat thickness were used for isothermal heat treatment study. However, since the beta-phase was still present after $200 \mathrm{~h}$, the lower bondcoat thickness should not have affected the results in this case.

Figure 7(b) shows the VPS bondcoat after isothermal heat treatment. Unlike the HVAF bondcoat, the dark gray alumina layer showed several oxide pegs into the bondcoat as also indicated by the arrows in the figure. This developed in a more non-uniform TGO as the heat exposure time increased. The thickness of the TGO layer in VPS bondcoats after $200 \mathrm{~h}$ was around $20 \mu \mathrm{m}$. This type of oxidation behavior in VPS bondcoats has been observed in previous studies as well and is understood to occur due to faster depletion of aluminum in the valleys on the bondcoat surface leading to formation of other oxides into the bondcoat thickness, despite the presence of beta-phase

Table 2 Some of the ISO 25178 feature parameters measured on the HVAF and VPS bondcoats in as-sprayed condition without grit blasting

\begin{tabular}{|c|c|c|c|}
\hline Parameter & Description & HVAF & VPS \\
\hline $\mathrm{Spd}, 1 / \mathrm{mm}^{2}$ & \multirow[t]{2}{*}{ Number of peaks per unit area } & \multirow[t]{2}{*}{81} & \multirow[t]{2}{*}{188} \\
\hline Density of peaks & & & \\
\hline $\mathrm{Spc}, 1 / \mu \mathrm{m}$ & \multirow[t]{2}{*}{ Arithmetic mean of the principle curvatures of peaks } & \multirow[t]{2}{*}{0.245} & \multirow[t]{2}{*}{0.288} \\
\hline Arithmetic mean & & & \\
\hline $\mathrm{S} 10 \mathrm{z}, \mu \mathrm{m}$ & \multirow{2}{*}{$\begin{array}{l}\text { Average value of the heights of the five peaks with the largest global peak } \\
\text { height added to the average value of the heights of the five pits with the } \\
\text { largest global pit height }\end{array}$} & \multirow[t]{2}{*}{42.9} & \multirow[t]{2}{*}{43.7} \\
\hline Ten point height & & & \\
\hline
\end{tabular}



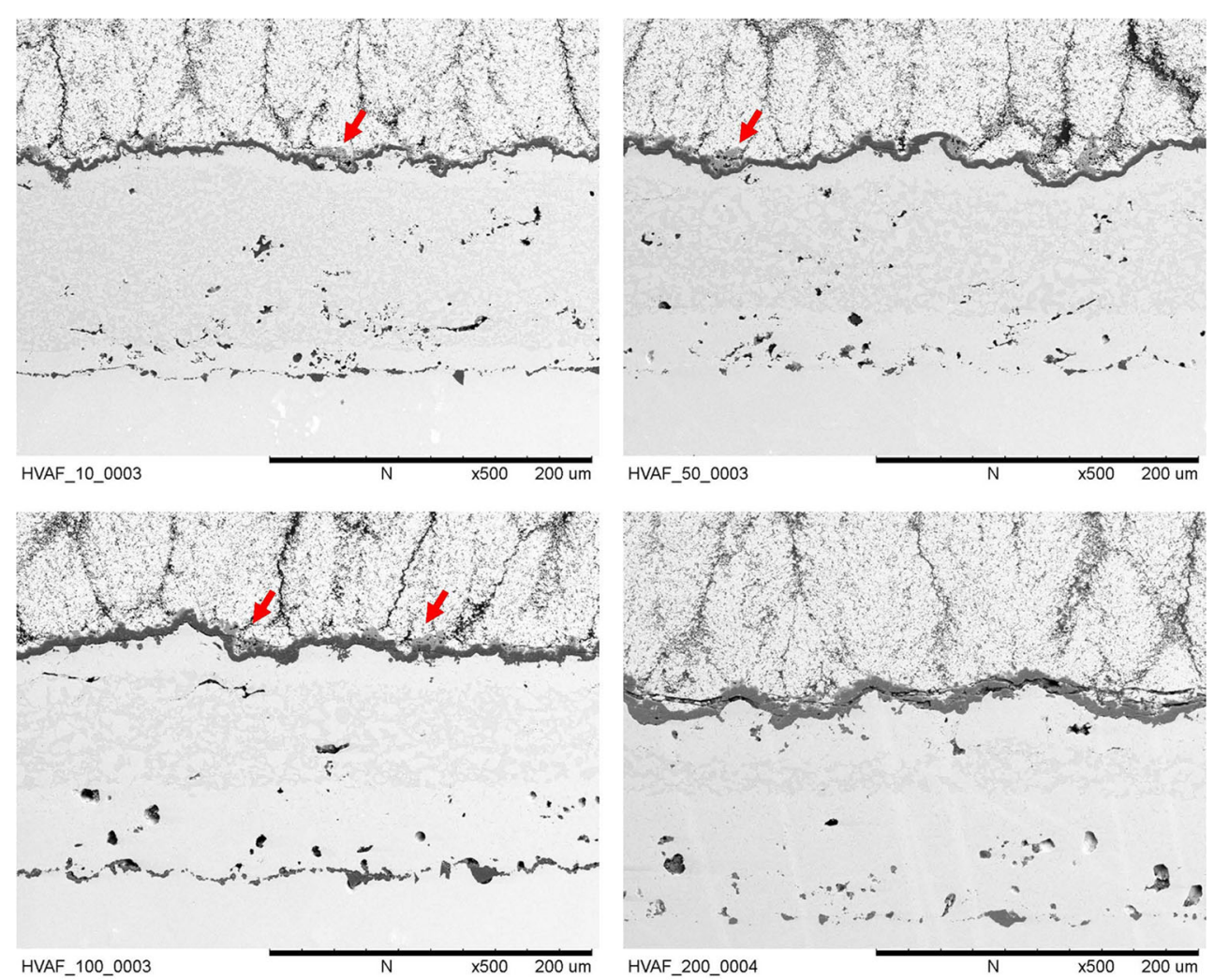

(a)
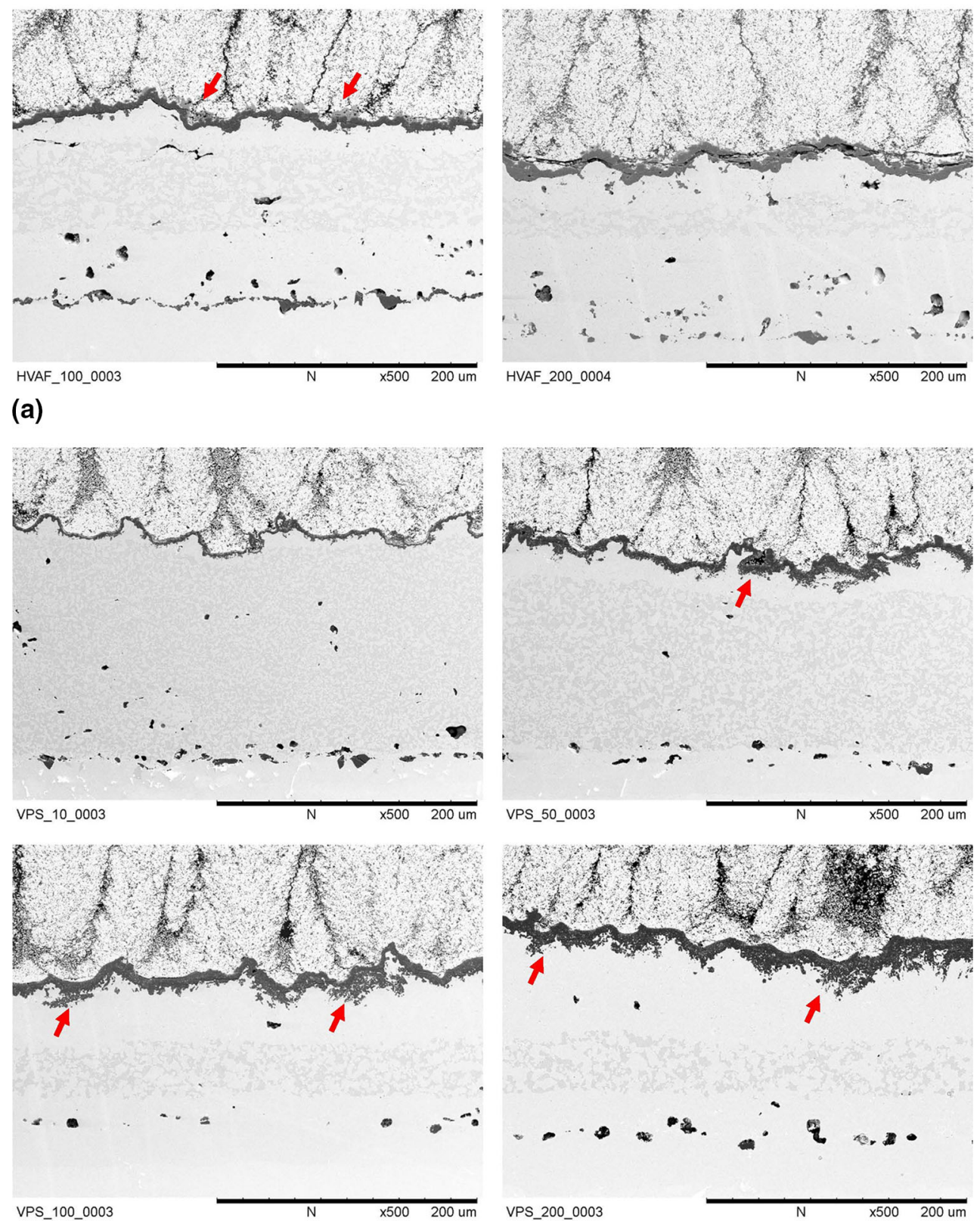

(b)

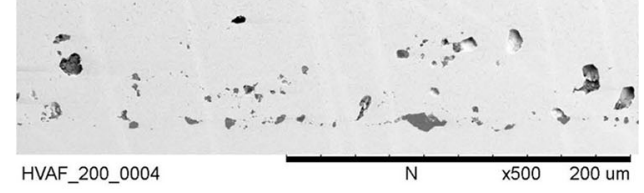




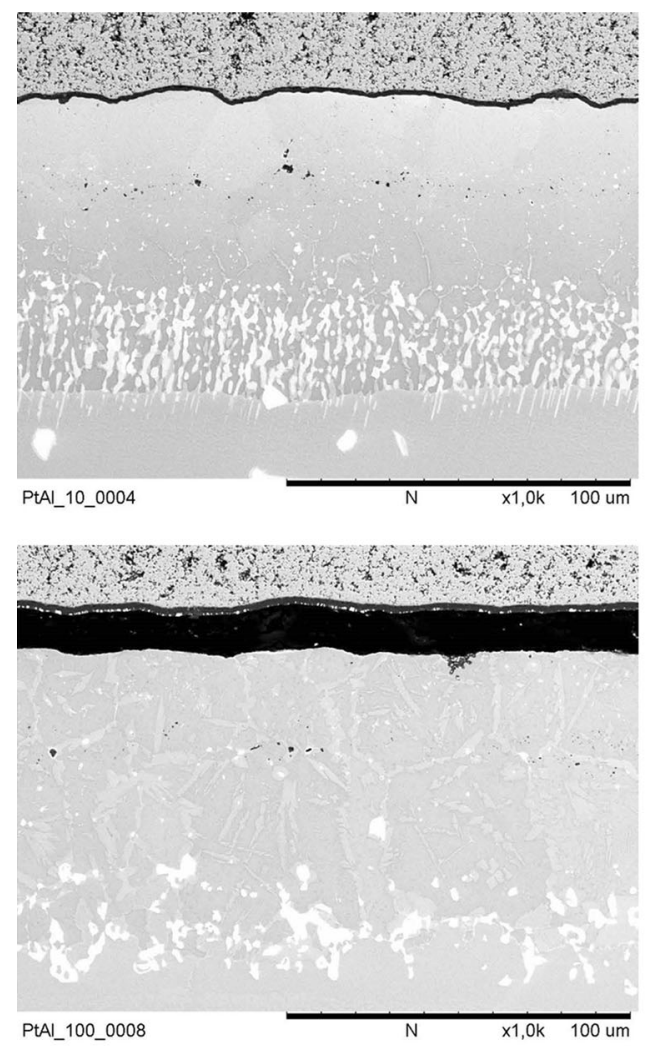

(c)
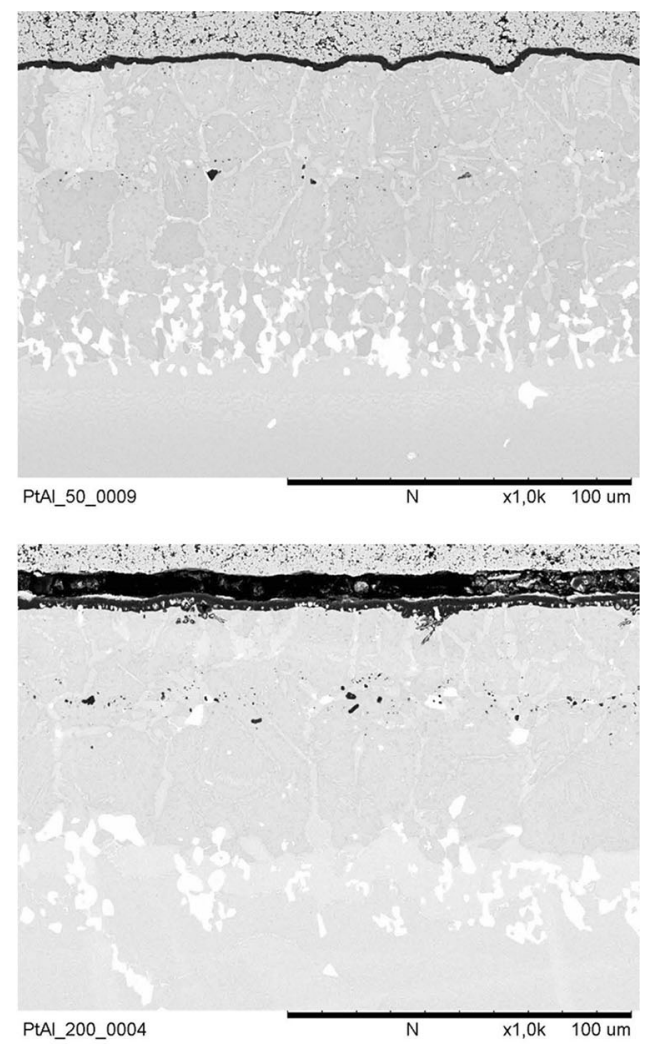

Fig. 7 continued

deeper into the bondcoat thickness ( $\operatorname{Ref} 25,26)$. This type of oxidation is of course not desired as it creates a thicker and uneven TGO layer which could cause additional stresses in the topcoat. These oxide pegs were also observed after TCF testing as shown in Fig. 6(b) which could have contributed to earlier failure of the VPS samples as compared to the HVAF samples. The oxide pegs could perhaps be diminished by optimizing the bondcoat surface roughness or chemical composition.

Figure 7(c) shows the diffusion bondcoat after isothermal heat treatment. A thin, dense and uniform layer of alumina can be observed in the images as expected for the diffusion bondcoat. Spallation of the topcoat occurred after 100 and $200 \mathrm{~h}$ of heat treatment, probably due to poor bonding in the as-sprayed condition as discussed earlier. The thickness of the TGO layer after $200 \mathrm{~h}$ was about 3-5 $\mu \mathrm{m}$. A slow growing dense alumina layer is typically desired for TBCs as it can provide the necessary oxidation protection without causing high stresses for a longer duration. The uniform and slow growing alumina layer was most probably the reason for high TCF lifetime of diffusion samples.

Figure 8 shows the microstructure cross-sectional images (top row) and top view images (bottom row) of the topcoats after heat treatment for $200 \mathrm{~h}$. Opening up of the column gaps due to sintering of the topcoat can be observed in all cases shown in the top row similar to the observations after TCF testing shown in Fig. 6. Merging of some columns can also be observed in the diffusion sample. These observations indicate that sintering had a major contribution to the changes in topcoat microstructure after TCF testing apart from the effect of expansion and contraction of the topcoat due to thermal cycling. The top view images shown in the bottom row in Fig. 8 were captured at the center of randomly selected columns. Again, very similar microstructures with similar porosity and particle sizes can be observed in all cases which was expected due to the similarity found in the as-sprayed condition as shown in Fig. 4. Significant sintering of the topcoat can be noted in all cases as the microstructure seems to be better cohered than in the as-sprayed condition with larger particles. The individual spherical-shaped particles present in the assprayed condition seemed to have fuse together and are not distinctly visible any longer. These changes in the topcoat microstructure after sintering were observed in previous work as well (Ref 20). These results show that the effect of sintering within the columns was similar and only intercolumnar sintering was different, which was expected as 

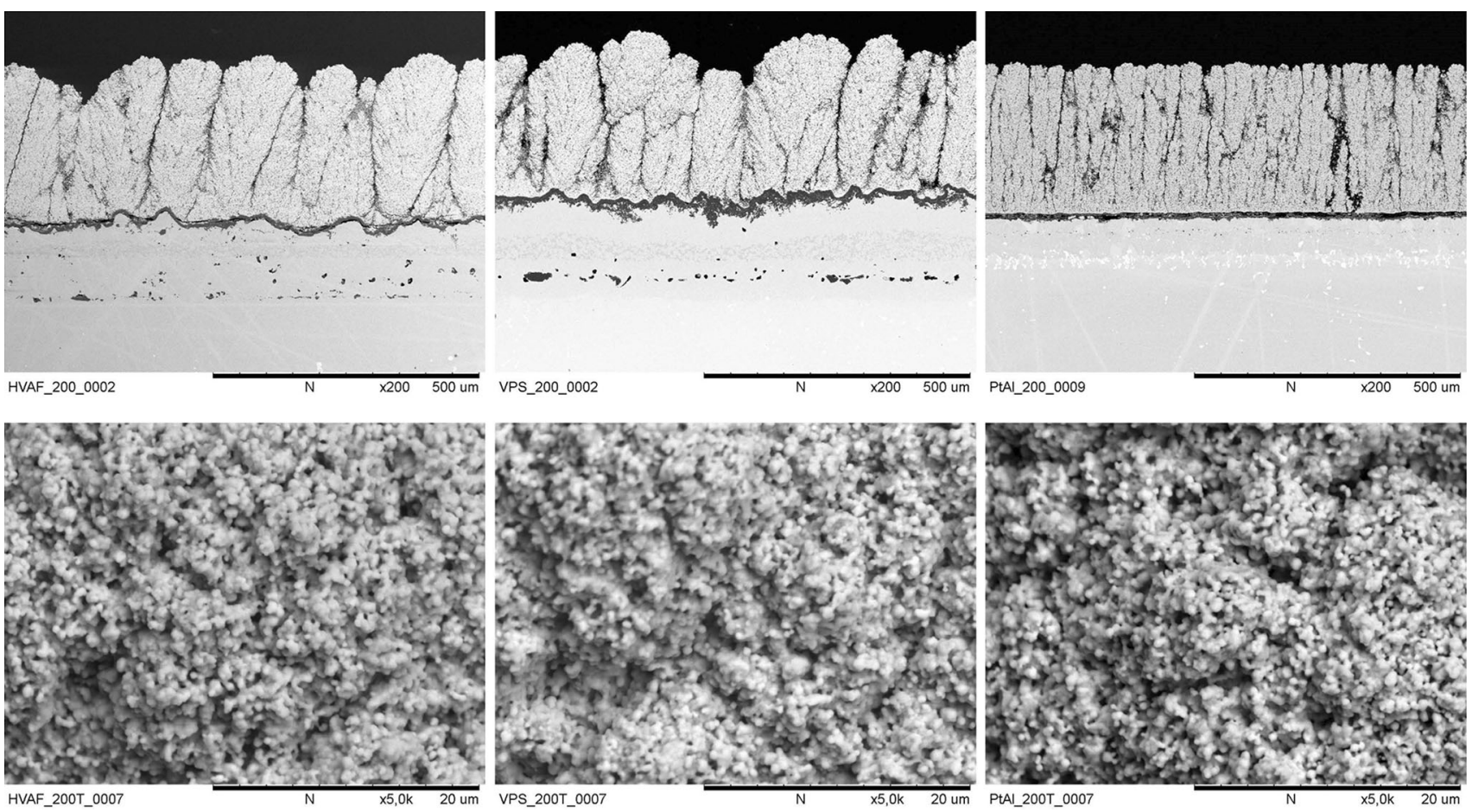

Fig. 8 Microstructure cross-sectional images (top row) and top view (bottom row) of the samples after isothermal heat treatment at $1100{ }^{\circ} \mathrm{C}$ (left) HVAF, (middle) VPS, and (right) diffusion with non-grit-blasted bondcoats

same topcoat spray parameters were used, but on samples with different bondcoat roughness resulting in different initial columnar microstructure.

\section{Summary and Conclusions}

In this work, NiCoCrAlY bondcoat deposited by HVAF were compared to commercial NiCoCrAlY bondcoat deposited by VPS and PtAl diffusion bondcoat. The YSZ topcoats were deposited by SPS using the same spray parameters in all cases. The effect of bondcoat microstructure and topcoat-bondcoat interface topography on topcoat microstructure and lifetime was discussed.

The results show that the bondcoat topography can significantly vary the column formation in topcoat microstructure. The smooth diffusion bondcoat resulted in a thin columnar structure, while the rough HVAF and VPS bondcoats resulted in wider columns even though same topcoat spray parameters were used.

The HVAF bondcoat showed better lifetime results than the VPS bondcoat, even though both of them were deposited using the same feedstock material. The diffusion bondcoat showed the highest TCF lifetime due to the different bondcoat chemistry. Light grit blasting of the bondcoat surface did not seem to influence the lifetime significantly, probably due to insufficient change in surface roughness after grit blasting making the effect of grit blasting insignificant.

The results indicate that HVAF could be a suitable process for bondcoat deposition in SPS TBCs as compared to VPS, due to its process characteristics (high velocity and low temperature) that makes possible to produce dense coatings with minimal effect of temperature on inflight particles.

Acknowledgments The authors would like to acknowledge The Knowledge Foundation for the funding of this research work. Thanks to Stefan Björklund and Kenneth Andersson at University West for the help with spraying and metallographic preparation, respectively.

Open Access This article is distributed under the terms of the Creative Commons Attribution 4.0 International License (http://crea tivecommons.org/licenses/by/4.0/), which permits unrestricted use, distribution, and reproduction in any medium, provided you give appropriate credit to the original author(s) and the source, provide a link to the Creative Commons license, and indicate if changes were made.

\section{References}

1. C.U. Hardwicke and Y.-C. Lau, Advances in Thermal Spray Coatings for Gas Turbines and Energy Generation: A Review, $J$. Therm. Spray Technol., 2013, 22(5), p 564-576

2. A. Feuerstein, J. Knapp, T. Taylor, A. Ashary, A. Bolcavage, and N. Hitchman, Technical and Economical Aspects of Current Thermal Barrier Coating Systems for Gas Turbine Engines by 
Thermal Spray and EBPVD: A Review, J. Therm. Spray Technol., 2008, 17(2), p 199-213

3. A. Ganvir, N. Curry, S. Björklund, N. Markocsan, and P. Nylén, Characterization of Microstructure and Thermal Properties of YSZ Coatings Obtained by Axial Suspension Plasma Spraying (ASPS), J. Therm. Spray Technol., 2015, 24(7), p 1195-1204

4. A. Ganvir, C. Kumara, M. Gupta, and P. Nylén, Thermal Conductivity in Suspension Sprayed Thermal Barrier Coatings: Modeling and Experiments, J. Therm. Spray Technol., 2017, 26, p 71-82

5. B. Bernard, A. Quet, L. Bianchi, A. Joulia, A. Malié, V. Schick, and B. Rémyd, Thermal Insulation Properties of YSZ Coatings: Suspension Plasma Spraying (SPS) Versus Electron Beam Physical Vapor Deposition (EB-PVD) and Atmospheric Plasma Spraying (APS), Surf. Coat. Technol., 2017, 318, p 122-128

6. N. Markocsan, M. Gupta, S. Joshi, P. Nylén, X.-H. Li, and J. Wigren, Liquid Feedstock Plasma Spraying: An Emerging Process for Advanced Thermal Barrier Coatings, J. Therm. Spray Technol., 2017, https://doi.org/10.1007/s11666-017-0555-4

7. A. Ganvir, N. Curry, S. Govindarajan, and N. Markocsan, Characterization of Thermal Barrier Coatings Produced by Various Thermal Spray Techniques Using Solid Powder, Suspension, and Solution Precursor Feedstock Material, Int. J. Appl. Ceram. Technol., 2016, 13(2), p 324-332

8. A.G. Evans, D.R. Mumm, J.W. Hutchinson, G.H. Meier, and F.S. Pettit, Mechanisms Controlling the Durability of Thermal Barrier Coatings, Prog. Mater. Sci., 2001, 46(5), p 505-553

9. A. Scrivani, U. Bardi, L. Carrafiello, A. Lavacchi, F. Niccolai, and G. Rizzi, A Comparative Study of High Velocity Oxygen Fuel, Vacuum Plasma Spray, and Axial Plasma Spray for the Deposition of CoNiCrAlY Bond Coat Alloy, J. Therm. Spray Technol., 2003, 12(4), p 504-507

10. M.P. Taylor, W.M. Pragnell, and H.E. Evans, The Influence of Bond Coat Surface Roughness on Chemical Failure and Delamination in TBC Systems, Mater. Corros., 2008, 59(6), p 508-513

11. M. Gupta, K. Skogsberg, and P. Nylén, Influence of TopcoatBondcoat Interface Roughness on Stresses and Lifetime in Thermal Barrier Coatings, J. Therm. Spray Technol., 2014, 23(12), p 170-181

12. K. Van Every, M.J.M. Krane, R.W. Trice, H. Wang, W. Porter, M. Besser, D. Sordelet, J. Ilavsky, and J. Almer, Column Formation in Suspension Plasma-Sprayed Coatings and Resultant Thermal Properties, J. Therm. Spray Technol., 2011, 20(4), p 817-828

13. P. Sokołowski, S. Kozerski, L. Pawłowski, and A. Ambroziak, The Key Process Parameters Influencing Formation of Columnar Microstructure in Suspension Plasma Sprayed Zirconia Coatings, Surf. Coat. Technol., 2014, 260, p 97-106

14. N. Curry, Z. Tang, N. Markocsan, and P. Nylén, Influence of Bond Coat Surface Roughness on the Structure of Axial Suspension Plasma Spray Thermal Barrier Coatings-Thermal and Lifetime Performance, Surf. Coat. Technol., 2015, 268, p 15-23
15. B. Bernard, L. Bianchi, A. Malié, A. Joulia, and B. Rémy, Columnar Suspension Plasma Sprayed Coating Microstructural Control for Thermal Barrier Coating Application, J. Eur. Ceram. Soc., 2016, 36, p 1081-1089

16. B. Bernard, A. Quet, L. Bianchi, V. Schick, A. Joulia, A. Malié, and B. Rémy, Effect of Suspension Plasma-Sprayed YSZ Columnar Microstructure and Bond Coat Surface Preparation on Thermal Barrier Coating Properties, J. Therm. Spray Technol., 2017, https://doi.org/10.1007/s11666-017-0584-z

17. P. Sokołowski, L. Pawłowski, D. Dietrich, T. Lampke, and D. Jech, Advanced Microscopic Study of Suspension PlasmaSprayed Zirconia Coatings with Different Microstructures, $J$. Therm. Spray Technol., 2016, 25(1-2), p 94-104

18. M. Gupta, Design of Thermal Barrier Coatings-A Modelling Approach, SpringerBriefs in Materials Springer, Berlin, 2015, p 28-29

19. N. Curry, K. VanEvery, T. Snyder, and N. Markocsan, Thermal Conductivity Analysis and Lifetime Testing of Suspension Plasma-Sprayed Thermal Barrier Coatings, Coatings, 2014, 4(3), p 630-650

20. M. Gupta, N. Markocsan, X.-H. Li, and R. Peng, Improving the Lifetime of Suspension Plasma Sprayed Thermal Barrier Coatings, Surf. Coat. Technol., 2017, https://doi.org/10.1016/j.surf coat.2017.07.078

21. E. Sadeghimeresht, N. Markocsan, and P. Nylén, Microstructure Effect of Intermediate Coat Layer on Corrosion Behavior of HVAF-Sprayed Bi-Layer Coatings, J. Therm. Spray Technol., 2017, 26, p 243-253

22. A. Ganvir, N. Markocsan, and S. Joshi, Influence of Isothermal Heat Treatment on Porosity and Crystallite Size in Axial Suspension Plasma Sprayed Thermal Barrier Coatings for Gas Turbine Applications, Coatings, 2017, 7(4), p 1-14

23. M. Ahrens, R. Vaßen, and D. Stöver, Stress Distributions in Plasma-Sprayed Thermal Barrier Coatings as a Function of Interface Roughness and Oxide Scale Thickness, Surf. Coat. Technol., 2002, 161, p 26-35

24. R. Vaßen, S. Giesen, and D. Stöver, Lifetime of Plasma-Sprayed Thermal Barrier Coatings: Comparison of Numerical and Experimental Results, J. Therm. Spray Technol., 2009, 18(5-6), p 835-845

25. A. Gil, V. Shemet, R. Vassen, M. Subanovic, J. Toscano, D. Naumenko, L. Singheiser, and W.J. Quadakkers, Effect of Surface Condition on the Oxidation Behaviour of MCrAlY Coatings, Surf. Coat. Technol., 2006, 201, p 3824-3828

26. P. Song, D. Naumenko, R. Vassen, L. Singheiser, and W.J. Quadakkers, Effect of Oxygen Content in NiCoCrAlY Bondcoat on the Lifetimes of EB-PVD and APS Thermal Barrier Coatings, Surf. Coat. Technol., 2013, 221, p 207-213 